\title{
Research on Thermal Comfort of Outdoor Space in Summer Urban Park: Take Mianyang Urban Park as an Example
}

\author{
Bin Cheng, Rongzhou Cheng, Xinyu Tang \\ College of Civil Engineering and Architecture, Southwest University of Science and Technology, Mianyang, China \\ Email: chengbin@swust.edu.cn
}

How to cite this paper: Cheng, B., Cheng, R.Z. and Tang, X.Y. (2020) Research on Thermal Comfort of Outdoor Space in Summer Urban Park: Take Mianyang Urban Park as an Example. Journal of Building Construction and Planning Research, $\mathbf{8}$, 161-179.

https://doi.org/10.4236/jbcpr.2020.83010

Received: April 8, 2020

Accepted: June 29, 2020

Published: July 2, 2020

Copyright $\odot 2020$ by author(s) and Scientific Research Publishing Inc. This work is licensed under the Creative Commons Attribution International License (CC BY 4.0).

http://creativecommons.org/licenses/by/4.0/

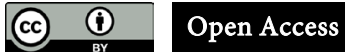

\begin{abstract}
One of the factors for the evaluation of the space environment is the comfort of outdoor activities spaces in urban parks. The space composed of different landscape elements has different microclimate environment. In this paper, in order to evaluate the role of thermal comfort in influencing resident's assessment of the outdoor space and activities of the park, a thermal comfort survey was conducted on the outdoor open space of Mianyang Urban Park in summer. In this article, meteorological surveys, questionnaire surveys and observation of park attendance are selected to collect data. The physiological equivalent temperature (PET) assessment was selected as the index to evaluate resident's thermal comfort level, and the comprehensive evaluation and analysis of the spatial thermal environment of different outdoor landscape elements in the park. The overall comfort of current visitors is mainly influenced by their subjective heat perception voting (TSV). In this article, we focus on providing microclimate adjustment considerations for urban park landscape design, and may help people understand the outdoor thermal comfort of Mianyang in summer, increase the using time of outdoor activities, and promote the use of outdoor space.
\end{abstract}

\section{Keywords}

Thermal Comfort, Outdoor Activities Space, Physiological Equivalent Temperature, Landscape Elements

\section{Introduction}

Urban parks are places where people can get close to nature in the city, especially mountains and rivers. It can provide recreation, leisure, entertainment, fitness 
and other functions for people living in the city [1]. The urban microclimate environment can affect people's feelings in the park's activity space; urban mountain parks are different from urban parks. They form a unique microclimate environment with unique terrain advantages and a natural ecological environment [2]. However, in the specific planning and design, the thermal comfort of users is often neglected, which greatly reduces the efficiency of space utilization. Therefore, it is necessary to understand the influence of microclimate factors on the spatial planning and design of urban mountain parks and the thermal comfort of users. The park's topography, water body, ground pavement, structures, plants, furniture pieces, etc. are the main types of garden elements in urban parks. In the planning and design stage of urban parks, we need to have reasonable arrangements for landscape elements and understand that various elements such as, the functions and expressions they undertake, and find the connection between them [3], so that they have a suitable composition combination in the space, so as to build a comfortable, beautiful and harmonious park landscape space. The design of the urban park landscape is the most important link in the creation of the park's microclimate environment, and it has a predictable direct impact and benefit on improving the environmental quality of the park space and the effective use of the park space [4].

The thermal comfort of urban outdoor space is affected by many factors. Different landscape factors affect the designer's ability to adapt to natural conditions in the design stage to a comfortable thermal environment using corresponding technical means [5]. Over the past ten years, more and more scholars have begun to study and pay attention. Mahmoud has studied the thermal comfort of urban parks in hot and arid areas, and has shown the urban residents thermal index PET (Physiological Equivalent Temperature) [6] and the perception of thermal voting [7]. By analyzing the spatial and temporal distribution characteristics of the thermal environment in Beijing's urban area, George et al. [8] found that the factors that directly affect the urban thermal environment are urban green space coverage, terrain, urban underlying surface factors, and heat emissions, in order to guide planners through urban factor to influence differences, and put forward the improvement and regulation of urban climate. Xu M, Hong B, Mi J, et al. [9] carried out research on outdoor thermal comfort in an urban park during winter in cold regions of China, Chen Yuanchao [10], established the ASV and Logic Logit model based on the outdoor thermal comfort evaluation index of the campus in Guangzhou area, and revealed that improving the ventilation conditions of the space and changing the site shading can have a greater impact on the thermal comfort of the outdoor space. Through research on the outdoor thermal environment of the residential area, Ma Xiaoyang [11] found that factors such as architecture, underlying surface properties, plant species and other factors will have an effect on the spatial thermal environment of the residential area, and summarized the Qiao-irrigation-grass model and Qiao-grass greening model. It has the best effect on improving the space thermal environ- 
ment. However, there is still little influence on the landscape factors of urban parks, especially the quantitative study of the combination of landscape elements in the space. The impact of landscape elements on the outdoor thermal environment needs to be supplemented by quantitative research based on the original qualitative research, using rational design thinking to improve the outdoor thermal environment of city parks and make the design of the park rule-based [12]. This paper attempts to carry out mathematical statistics through actual measurement of climate data, and make quantitative research on multiple landscape elements. It is expected to find the relationship between the actual climate environment and meteorological parameters tested and the composition of urban park landscapes. Further research on the design of park landscape elements. The role of the behavior and comfort of the specific spatial environment of the park [13].

At present, in domestic and foreign studies, the indoor thermal environment of buildings has been quite perfect, but the research on the climate adaptability characteristics of urban park activity spaces in typical outdoor areas is still lacking. Although existing research scholars have begun to pay attention to the urban microclimate from a technical perspective, less attention has been paid to the microclimate of the specific urban land, such as mountainous city parks. Therefore, this paper attempts to focus on the local climate through the thermal comfort of the urban park activity space. The adaptability study summarizes the scientific planning strategy of outdoor activity space in mountainous city parks in Mianyang City, and finds the optimal model of thermal environment suitable for the activity space of mountainous parks.

In this article, we take the physiological equivalent temperature (PET) as an index to evaluate the thermal comfort of the environment. The physiological equivalent temperature refers to various microclimate factors relating to physiological response of human body, such as different combinations of temperature, humidity, wind speed and solar radiation. The relationship between its thermal sensation level and physiological stimulus response is shown in Table 1. Meanwhile,

Table 1. The PET value corresponds to thermal sensation level and psysiological stress response.

\begin{tabular}{ccc}
\hline PET $/{ }^{\circ} \mathrm{C}$ & Thermal sensation & Psychological stress response \\
\hline$\leq 4$ & Very cold & Extreme cold stress \\
$4-8$ & Cold & Strong cold stress \\
$8-13$ & A bit cold & Cold stress \\
$13-18$ & Comfortable & Mild cold stress \\
$18-23$ & A bit warm & No heat stress \\
$23-29$ & Warm & Mild heat stress \\
$29-35$ & Hot & Moderate heat stress \\
$35-41$ & A bit hot & Strong heat stress \\
$\geq 41$ & Very hot & Extreme heat stress \\
\hline
\end{tabular}


it also integrates various reactions of human activity and thermal physiology, such as: thermal resistance of clothes, human parameters of human metabolism rate [14]. The object of this research is Mianyang Urban Park. During the development of Mianyang City, urban parks are consider as an open space of green space, they play important roles in improving the function of the urban ecosystem. They affected by multiple influences of environment, such as geological landform and human development, for its unique geographical location. The parks spontaneously formed a spatial combination method for the local damp and hot environment which is worth studying by scholars [15].

\section{Experiment Overview}

\subsection{Overview of Experimental Subjects}

Mianyang, is located in the northwest of the Sichuan province. It is a typical subtropical humid monsoon climate. The summer is hot and rainy, and the winter is mild with little rain. The average annual temperature is about $14.7^{\circ} \mathrm{C}$ $17.3^{\circ} \mathrm{C}$, and the average annual precipitation is $825.8-1417 \mathrm{~mm}$. We selected four major urban mountain parks as the research objects. The specific distribution location is shown in Figure 1.

Fule Mountain $\left(104.73^{\circ}\right.$ east longitude, $31.48^{\circ}$ north latitude) got its name because of Liu Bei's "Fu Zai, Today's Joy!" Built on the mountain, following the nature, using the two elements of mountains and waters, and relying on the classical gardening techniques to build a park featuring mountains and forests. $\mathrm{Xi}$ shan Park is located in the west of Mianyang City $\left(104.73^{\circ}\right.$ east longitude, $31.48^{\circ}$ north latitude). The famous historical figures Yang Xiong and Jiang Wan are

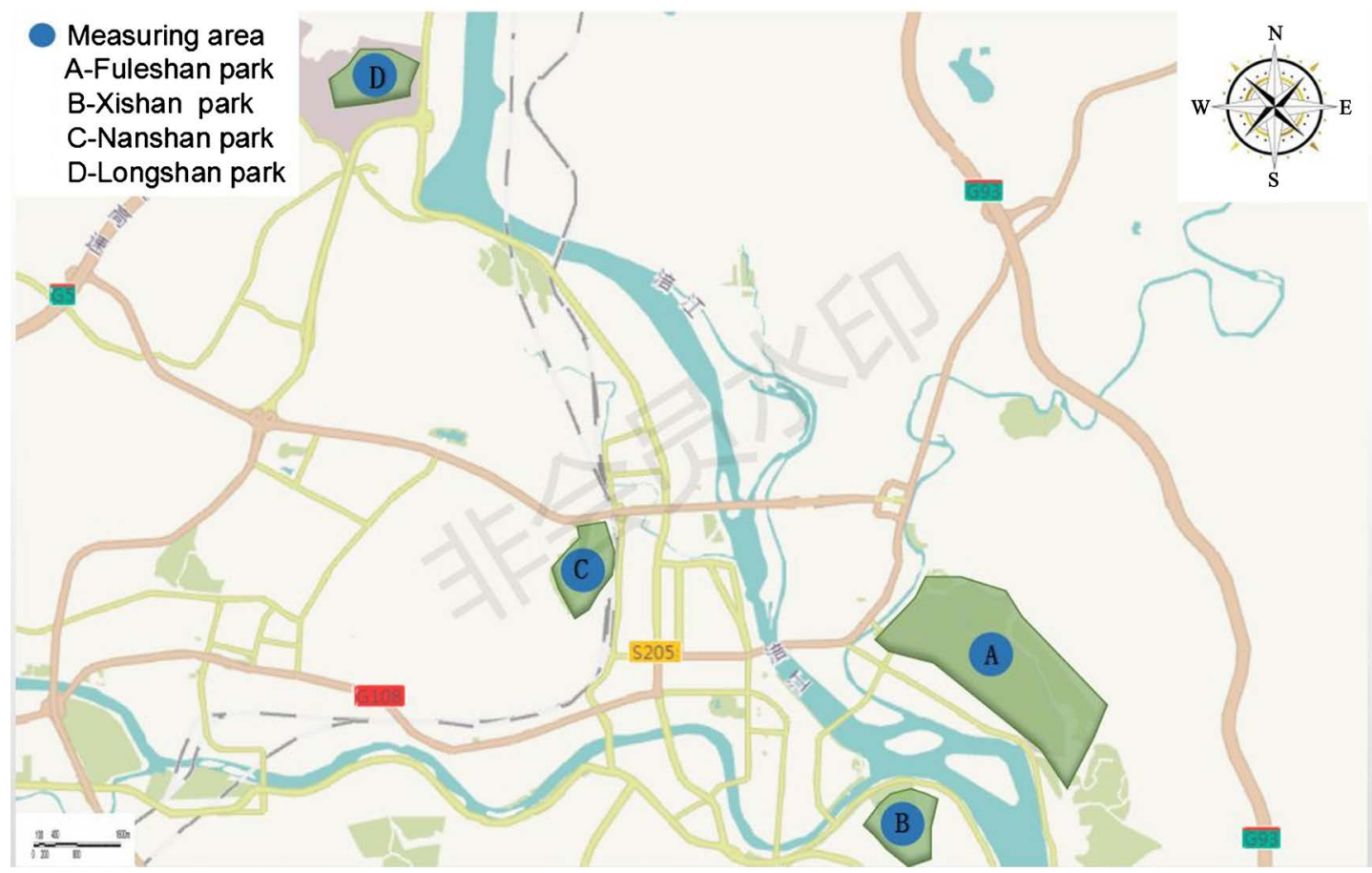

Figure 1. The location of four mountain parks in Mianyang City. 
buried in this park, which has been famous since ancient times. Xishan Mountain Park, because of the existence of the Jade Girl Spring, makes the interdependence between mountains and water more characteristic of a waterscape park. Taking Xishan Park as the research object of Mianyang City Park is also more representative. The distribution of the main test points in the four parks is shown in Figure 2 after summarizing the experimental scenarios during the test.

\subsection{Experimental Content}

In this test, four measuring points were arranged in four urban parks for fixedpoint observation. Observation instruments were set at distribution squares, open lawns, under the shade of trees, at the edge of water bodies, etc. The typical meteorological day in summer was selected as the experimental date, and the
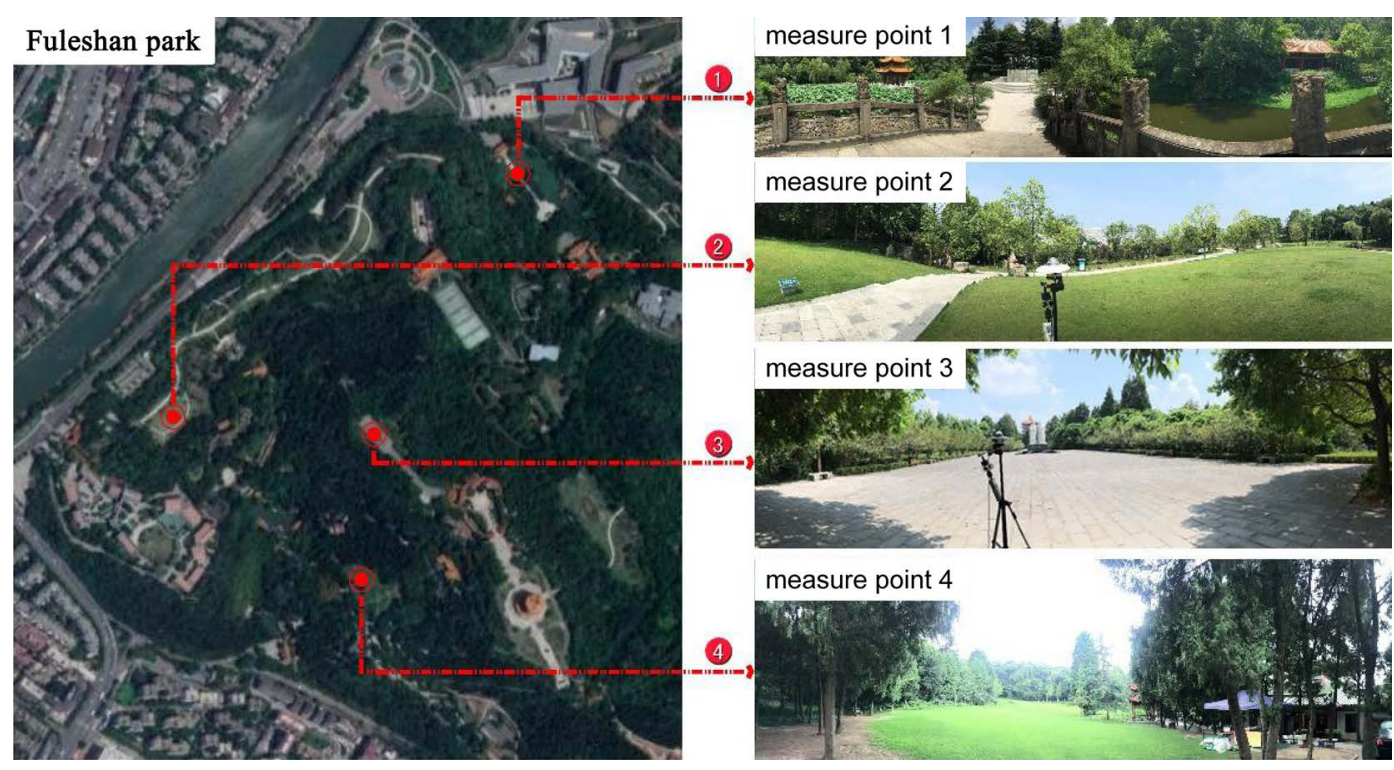

(a)

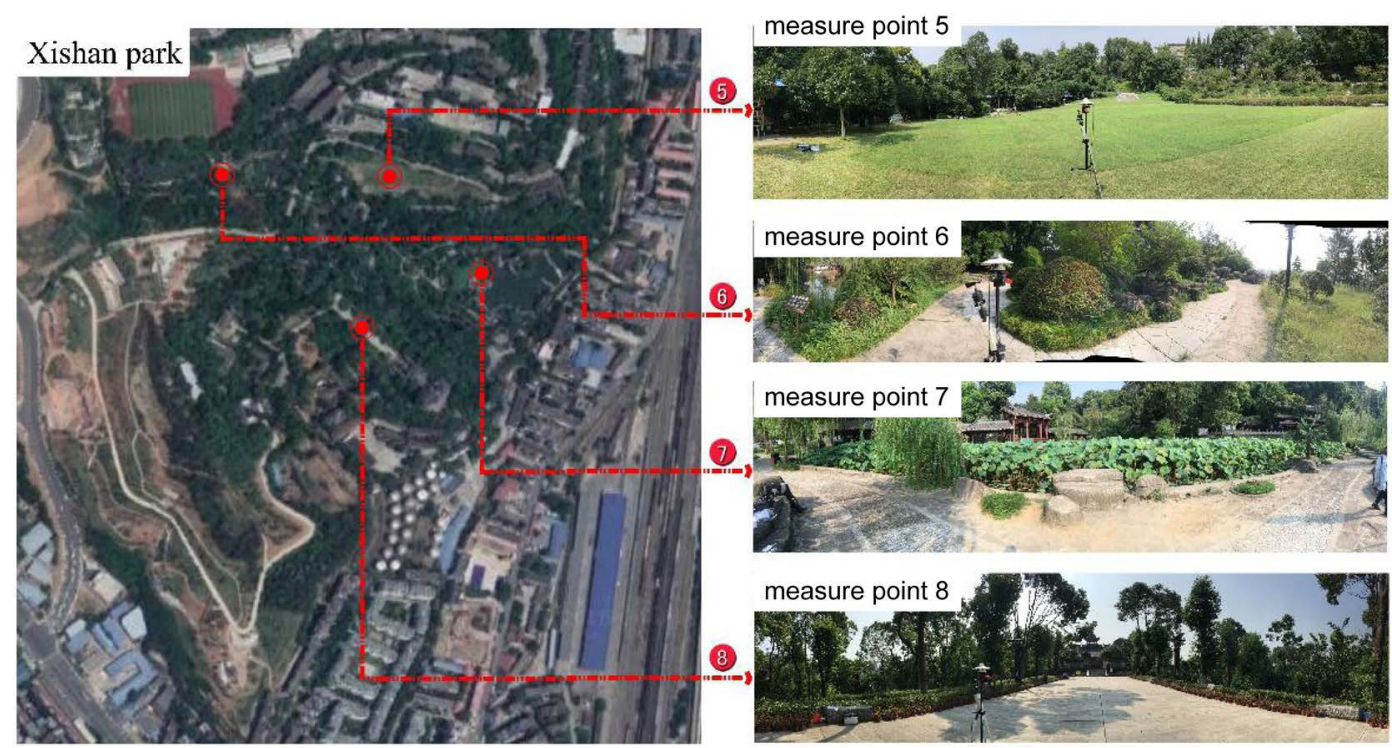

(b) 


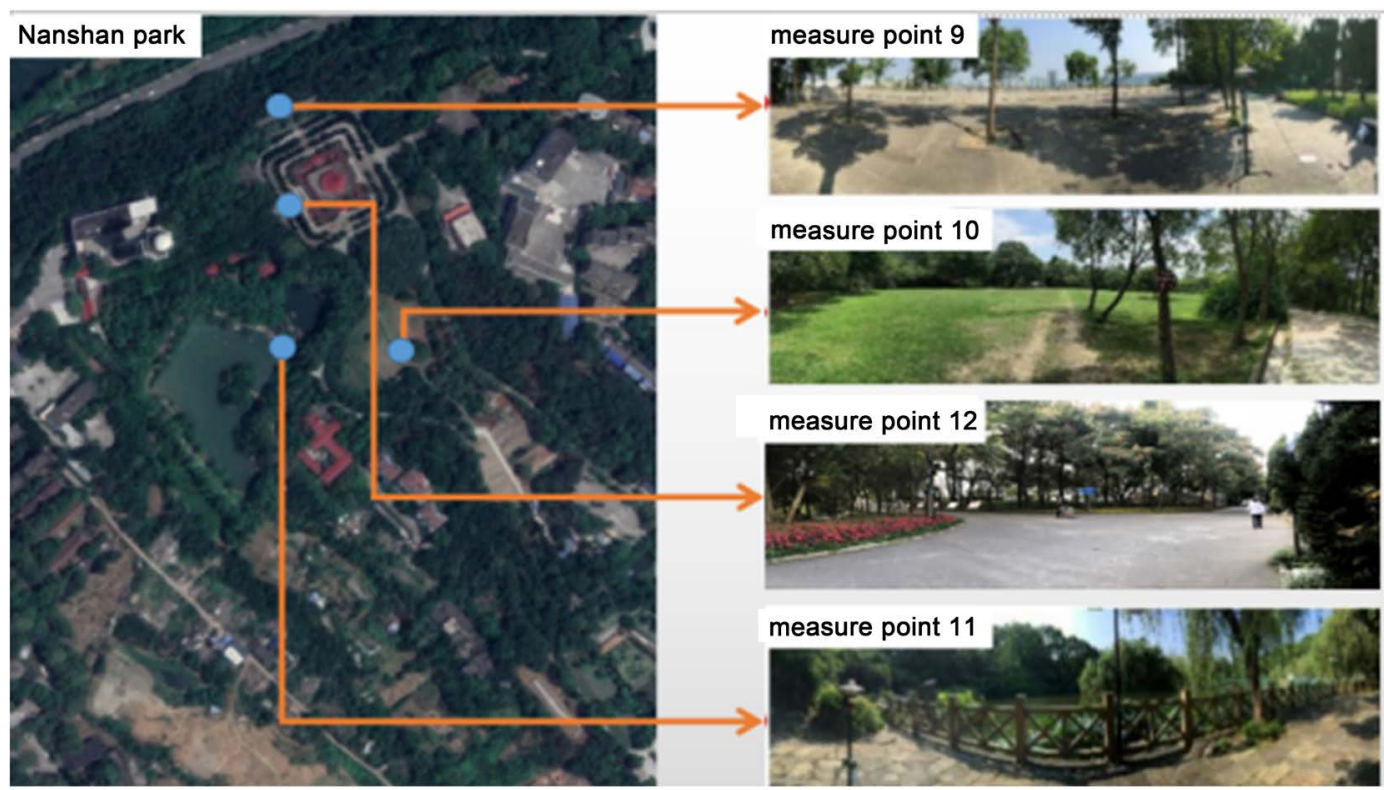

(c)

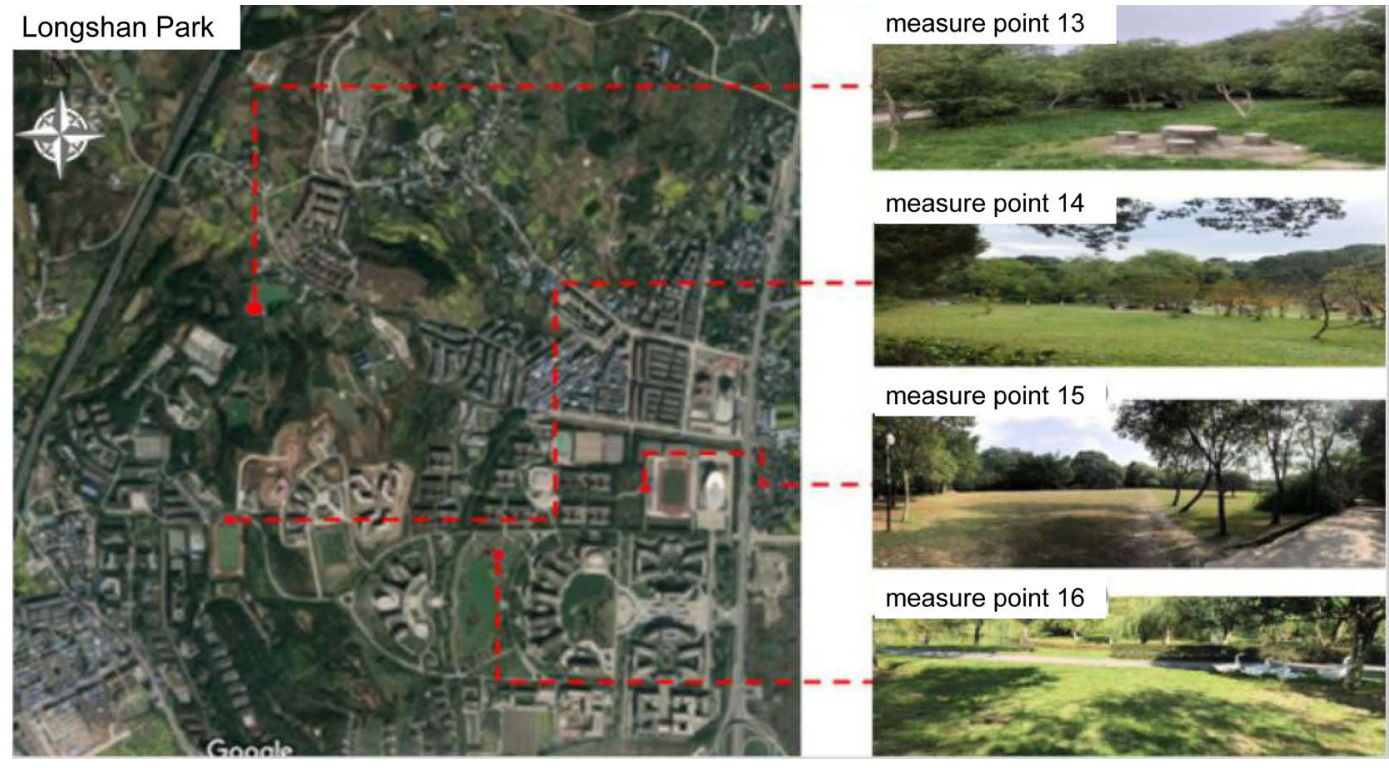

(d)

Figure 2. The layout of the test point. (a) Fuleshan Park; (b) Xishan Park; (c) Nanshan Park; (d) Longshan Park.

experimental time was 9: From 00 to 18:00, record the solar radiation, air temperature, relative humidity, wind speed and black ball temperature data at the measuring point at a height of $1.2 \mathrm{~m}$ every twenty minutes. The detailed test point distribution is shown in Figure 3. The instruments and performance parameters used in the measurement are shown in Table 2. Table 2 measures instruments and index parameters.

\subsection{Layout of Measuring Points}

This field survey selected the typical summer weather in Mianyang City in June 
2018, conducted climatic data measurement of specific spatial activities in the four parks, distributed questionnaires to recreational visitors, and conducted hot-feel voting and statistics of the number of people. The three parks were observed and counted for three consecutive days. The physical morphological data of the influencing elements of the park activity space test points are shown in Table 3.

We selected the main activities space for tourists as measuring points. We selected sixteen recreational space samples in four urban parks in Mianyang, and the area of each space is greater than $100 \mathrm{~m}^{2}$. We define the boundaries according to the function of the space and the actual using. In this study, we mainly focus on the underlying surface, plant cover, water factor and space boundary on human thermal comfort.

\subsection{Measurement Data}

By continuously observing the four urban parks in the typical summer days in Mianyang area, the average values of air temperature, solar radiation, black ball temperature, air relative humidity, and wind speed in 16 spaces were counted, and the PET value of each period was calculated using the Ray Man model. The specific test data level statistical analysis results are shown in Table 4. From the data point of view, because each space has a different composition of spatial elements, the climate data is very different, but from the perspective of PET value, the environmental comfort of each space is good or bad, so we explore each space. The research on the impact of different landscape factors on the thermal

Table 2. Main measuring instruments and index parameters.

\begin{tabular}{|c|c|c|c|c|c|}
\hline NO & Instruments & Parameters & Range & Precision & Acquisition methods \\
\hline \multirow{3}{*}{1} & Testo 480 & Air temperature $\left({ }^{\circ} \mathrm{C}\right)$ & $-10-45$ & \pm 0.5 & Automatic \\
\hline & & Relative humidity (\%) & $0-100$ & $\pm 5 \%$ & Automatic \\
\hline & & Wind speed $(\mathrm{m} / \mathrm{s})$ & $0-30$ & \pm 0.1 & Automatic \\
\hline 2 & AZ8758 & Globe temperature $\left({ }^{\circ} \mathrm{C}\right)$ & $-10-100$ & \pm 1.5 & Automatic \\
\hline 3 & JTTS-01 & Solar radiation $\left(\mathrm{W} / \mathrm{m}^{2}\right)$ & $0-2000$ & $\pm 5 \%$ & Automatic \\
\hline 4 & VC302B & Surface temperature $\left({ }^{\circ} \mathrm{C}\right)$ & $-30-350$ & \pm 2 & Manual \\
\hline \multirow[t]{2}{*}{5} & & & & & \\
\hline & & AZ8758 & \multicolumn{2}{|c|}{ JTTS-01 } & Testo 480 \\
\hline
\end{tabular}


Table 3. Data statistics of measuring points.

\begin{tabular}{|c|c|c|c|c|c|c|}
\hline \multirow{2}{*}{$\begin{array}{l}\text { Measuring } \\
\text { point Tepes of } \\
\text { landscape }\end{array}$} & \multirow{2}{*}{$\begin{array}{l}\text { Water area } \\
\qquad\left(\mathrm{m}^{2}\right)\end{array}$} & \multirow{2}{*}{$\begin{array}{l}\text { Shadowing area } \\
\qquad\left(\mathrm{m}^{2}\right)\end{array}$} & \multicolumn{2}{|c|}{$\begin{array}{l}\text { Underlay surface area } \\
\qquad\left(\mathrm{m}^{2}\right)\end{array}$} & \multicolumn{2}{|c|}{ Edge length (m) } \\
\hline & & & $\begin{array}{l}\text { Stone } \\
\text { brick }\end{array}$ & lawn & $\begin{array}{c}\text { Plant } \\
\text { boundary }\end{array}$ & $\begin{array}{l}\text { Pavement } \\
\text { boundary }\end{array}$ \\
\hline 1 & 5.00 & 4.00 & 60.00 & 35.00 & 20.00 & 2.00 \\
\hline 2 & 0.00 & 0.00 & 10.00 & 90.00 & 15.00 & 15.00 \\
\hline 3 & 7.00 & 10.00 & 40.00 & 53.00 & 10.00 & 10.00 \\
\hline 4 & 8.00 & 9.00 & 75.00 & 17.00 & 30.00 & 5.00 \\
\hline 5 & 20.00 & 19.00 & 70.00 & 10.00 & 25.00 & 8.00 \\
\hline 6 & 30.00 & 11.00 & 60.00 & 10.00 & 12.00 & 8.00 \\
\hline 7 & 0.00 & 2.00 & 22.00 & 88.00 & 20.00 & 20.00 \\
\hline 8 & 12.00 & 9.00 & 20.00 & 68.00 & 20.00 & 20.00 \\
\hline 9 & 10.00 & 12.00 & 75.00 & 15.00 & 14.00 & 5.00 \\
\hline 10 & 18.00 & 20.00 & 60.00 & 22.00 & 6.00 & 8.00 \\
\hline 11 & 0.00 & 7.00 & 50.00 & 50.00 & 10.00 & 10.00 \\
\hline 12 & 18.00 & 13.00 & 76.00 & 6.00 & 15.00 & 0.00 \\
\hline 13 & 0.00 & 1.00 & 5.00 & 95.00 & 5.00 & 15.00 \\
\hline 14 & 0.00 & 8.00 & 25.00 & 75.00 & 0.00 & 15.00 \\
\hline 15 & 14.00 & 15.00 & 56.00 & 30.00 & 20.00 & 4.00 \\
\hline 16 & 25.00 & 18.00 & 30.00 & 45.00 & 10.00 & 8.00 \\
\hline
\end{tabular}

Table 4. Measured data.

\begin{tabular}{ccccccc}
\hline & $\begin{array}{c}\text { Air } \\
\text { temperature } \\
\left({ }^{\circ} \mathrm{C}\right)\end{array}$ & $\begin{array}{c}\text { Solar } \\
\text { radiation } \\
\left(\mathrm{W} / \mathrm{m}^{2}\right)\end{array}$ & $\begin{array}{c}\text { Globe } \\
\text { temperature } \\
\left({ }^{\circ} \mathrm{C}\right)\end{array}$ & $\begin{array}{c}\text { Relative } \\
\text { humidity }(\%)\end{array}$ & $\begin{array}{c}\text { Wind speed } \\
(\mathrm{m} / \mathrm{s})\end{array}$ & $\begin{array}{c}\text { PET value } \\
\left({ }^{\circ} \mathrm{C}\right)\end{array}$ \\
\hline 1 & 39.69 & 670.75 & 48,52 & 47.96 & 0.00 & 38.68 \\
2 & 41.28 & 672.01 & 50.23 & 41.17 & 0.28 & 42.39 \\
3 & 37.02 & 588.91 & 48.74 & 49.14 & 0.00 & 45.80 \\
4 & 38.80 & 647.67 & 44.02 & 46.08 & 0.16 & 41.83 \\
5 & 36.72 & 494.51 & 42.25 & 49.92 & 0.00 & 40.78 \\
6 & 35.34 & 432.90 & 39.62 & 53.56 & 0.05 & 37.93 \\
7 & 38.29 & 452.86 & 41.26 & 47.76 & 0.15 & 38.70 \\
8 & 36.47 & 437.67 & 41.28 & 49.96 & 0.13 & 44.00 \\
9 & 38.27 & 562.31 & 41.83 & 46.67 & 0.00 & 41.76 \\
10 & 39.13 & 644.93 & 46.63 & 45.17 & 0.00 & 40.60 \\
11 & 37.49 & 584.50 & 42.59 & 44.950 & 0.00 & 38.67 \\
12 & 38.11 & 522.21 & 43.30 & 41.23 & 0.01 & 42.44 \\
13 & 35.73 & 588.42 & 41.69 & 45.17 & 0.27 & 39.34 \\
14 & 38.77 & 650.81 & 48.54 & 40.74 & 0.49 & 44.55 \\
15 & 38.48 & 677.47 & 45.43 & 40.61 & 0.48 & 42.23 \\
16 & 36.22 & 650.36 & 43.04 & 50.83 & 0.20 & 40.24 \\
\hline & & & & & &
\end{tabular}


environment is meaningful. We can learn from Cheng Bin's Thermal comfort in urban mountain parks in the hot summer and cold winter climate, the neutral PET range in Mianyang in summer is $22.06^{\circ} \mathrm{C}-31.24^{\circ} \mathrm{C}$ [16]. When the actual PET value in the space is closer to the neutral value, we say that the better the space environment.

\section{Research on Data Related to Spatial Elements and Human Behavior}

\subsection{Correlation Analysis}

In order to study whether the spatial environmental factors of urban parks will affect the behavior of recreational people, we first use data analysis software to calculate and analyze the correlation between the environmental factors in a specific space and the average daily PET value of the space calculated based on the measured data. When the absolute value of the calculated correlation coefficient approaches 1.0, it means that the correlation between the two sets of data is stronger; the closer the significance value is to 0 , the more significant the correlation between the data. The correlation between shading and PET values is shown in Figure 3. The correlation between water area and PET values is shown in Figure 4. The correlation between hard area a and PET values is shown in Figure 5. The correlation between grassland area and PET values is shown in Figure 6. The correlation between Plant boundary length and PET values is shown in Figure 7. The correlation between Pavement boundary length and PET values is shown in Figure 8. The correlation between the length of the structure boundary and PET values is shown in Figure 9. The correlation analysis of landscape elements and PET value of activity space is shown in Table 5 .

According to the results of the correlation analysis, among all the factors, there are significant correlations between the area of the water body, the degree of occlusion above the space and the nature of the underlying surface, and the number of people in space activities. It shows a negative correlation, that is to say, in summer, the larger the area of water in the unit space, the lower the physiological

Table 5. The correlation between landscape elements and PET value of activity space.

\begin{tabular}{cccc}
\hline Landscape element variate & Variable & $\mathbf{R}^{2}$ & $\begin{array}{c}\text { Statistical } \\
\text { significance Sig. }\end{array}$ \\
\hline Water & Water area & -0.884 & 0.000 \\
Solar shading & Shadowing area & -0.934 & 0.000 \\
Underlying surface & Lawn area & -0.707 & 0.020 \\
& Stone brick area & 0.856 & 0.010 \\
Enviromental border & Plant boundary length & -0.132 & 0.626 \\
& Pavement boundary length & 0.582 & 0.180 \\
& Structure boundary length & -0.029 & 0.914 \\
\hline
\end{tabular}

Sig. Extremely significant level $\leq 0.01^{* *}$. Sig. $<0.05$ significant level. 


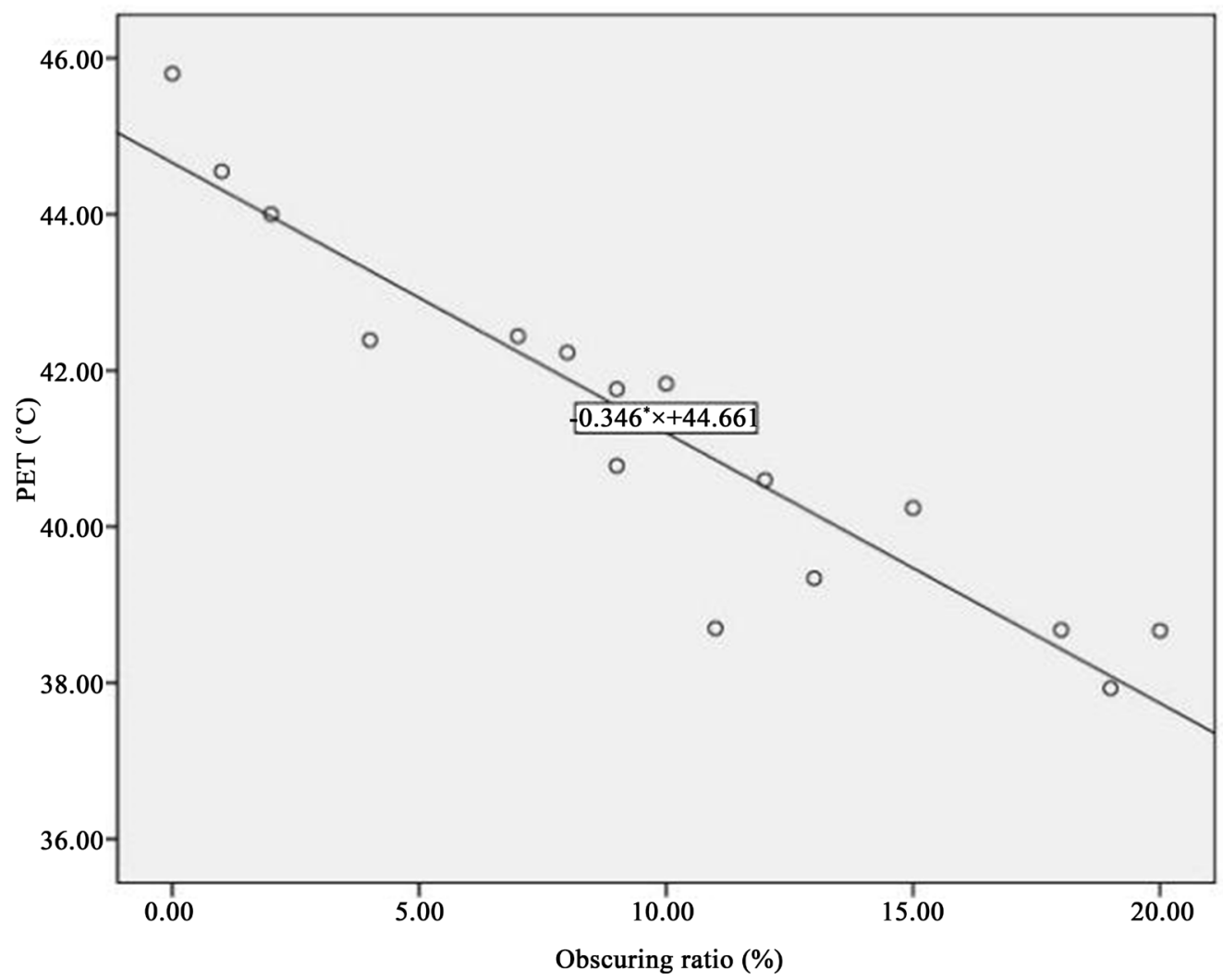

Figure 3. Correlation between shading and PET.

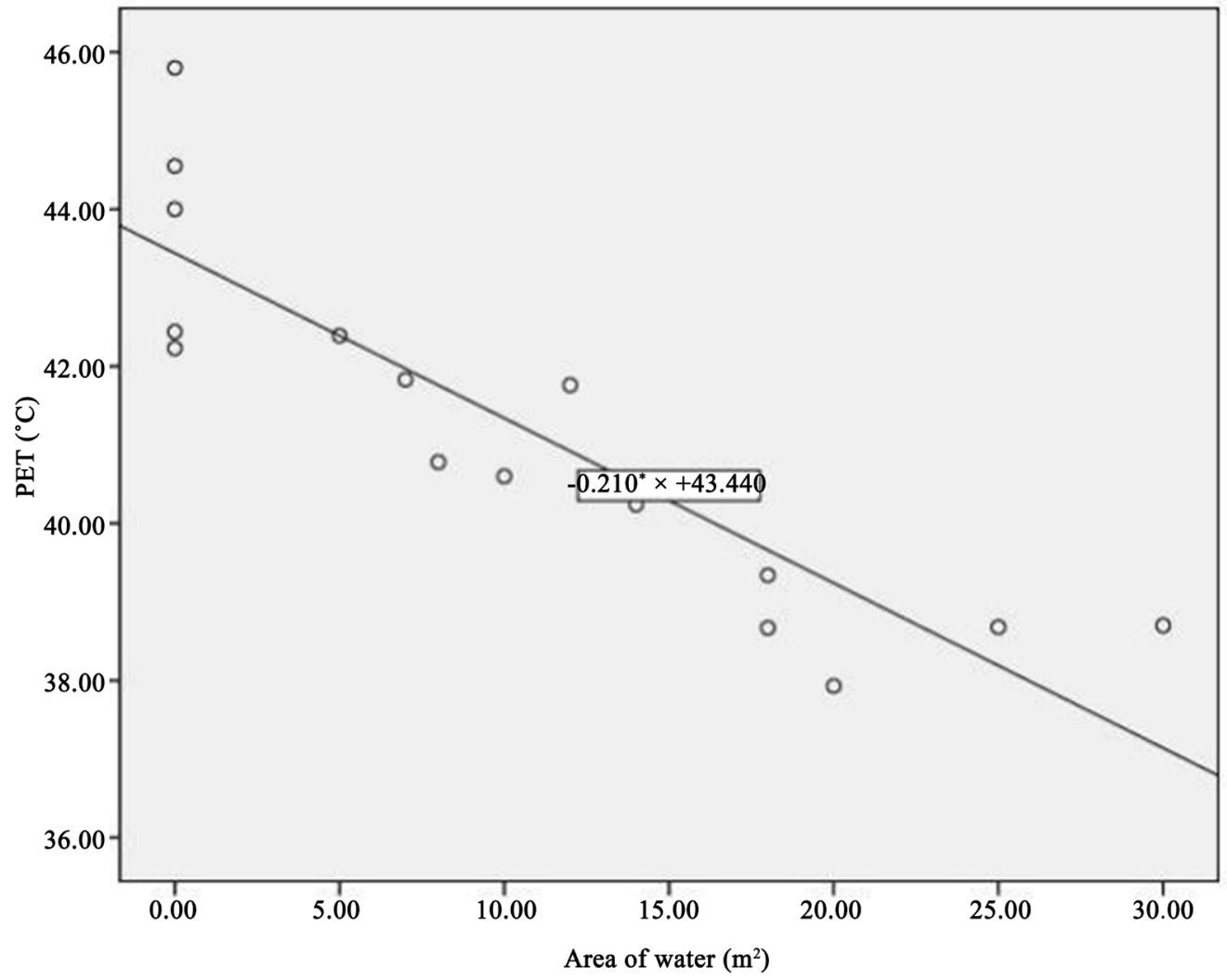

Figure 4. Correlation between water area and PET. 


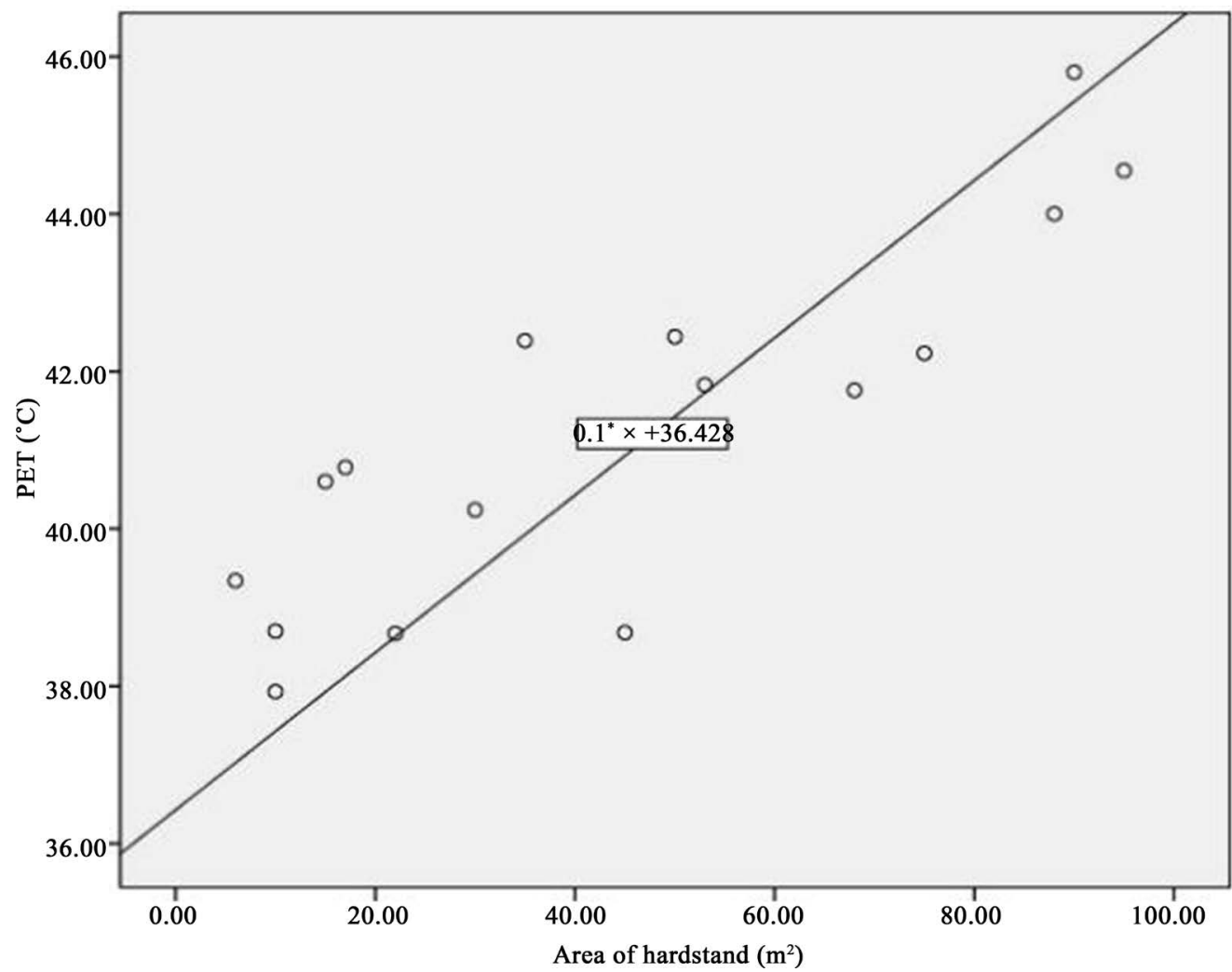

Figure 5. Correlation between hard area and PET.

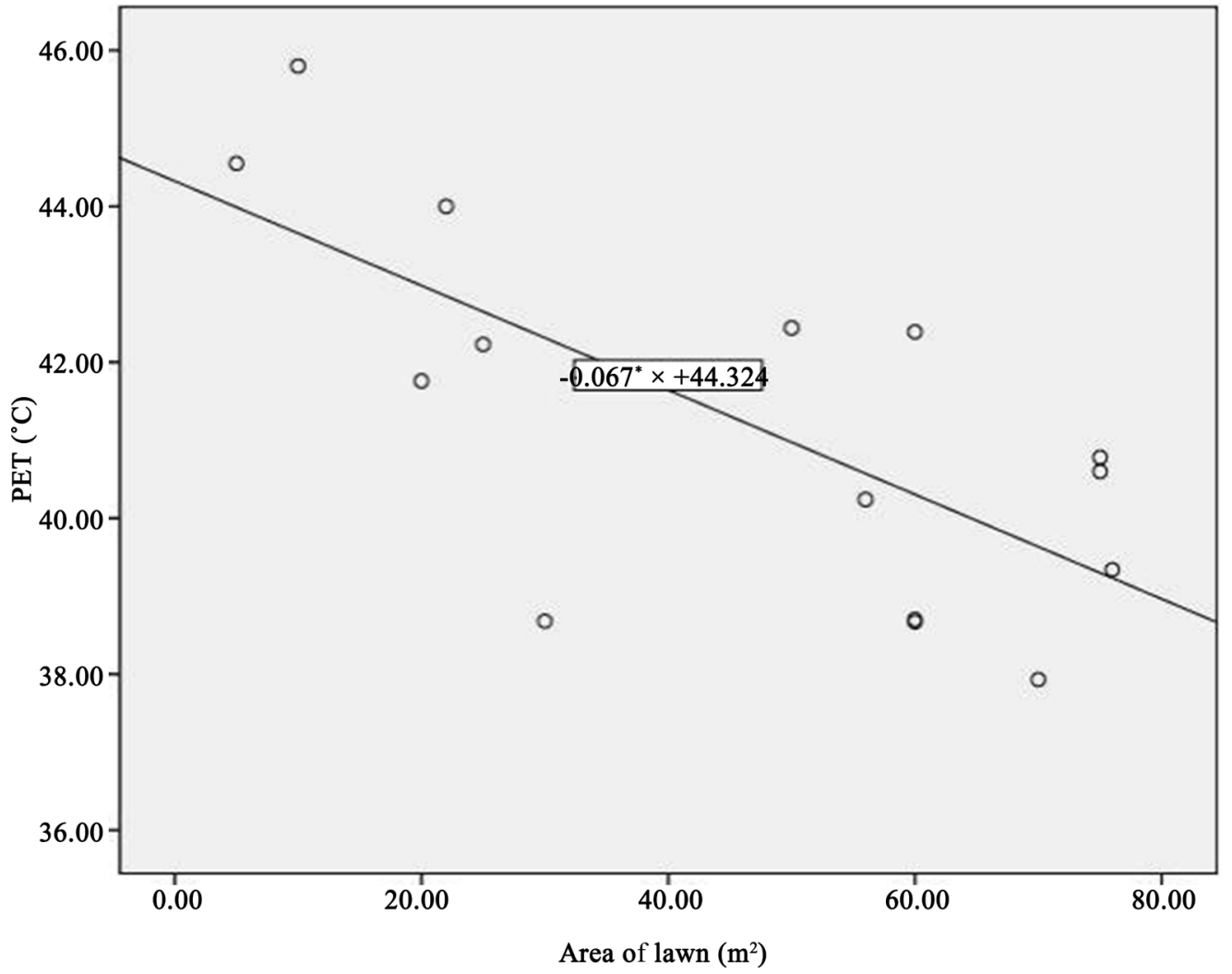

Figure 6. Correlation between grassland area and PET. 


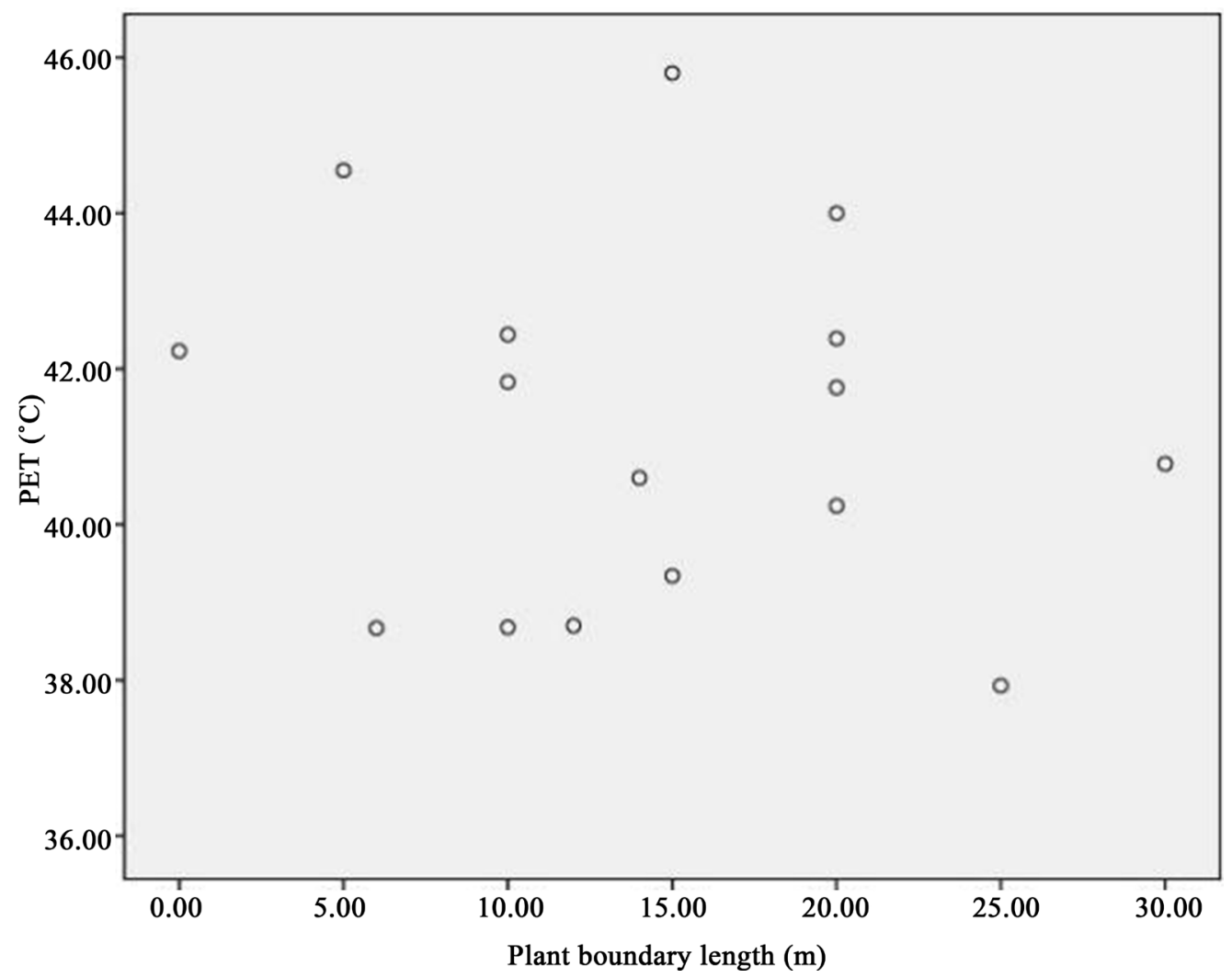

Figure 7. Correlation between plant boundary length and PET.

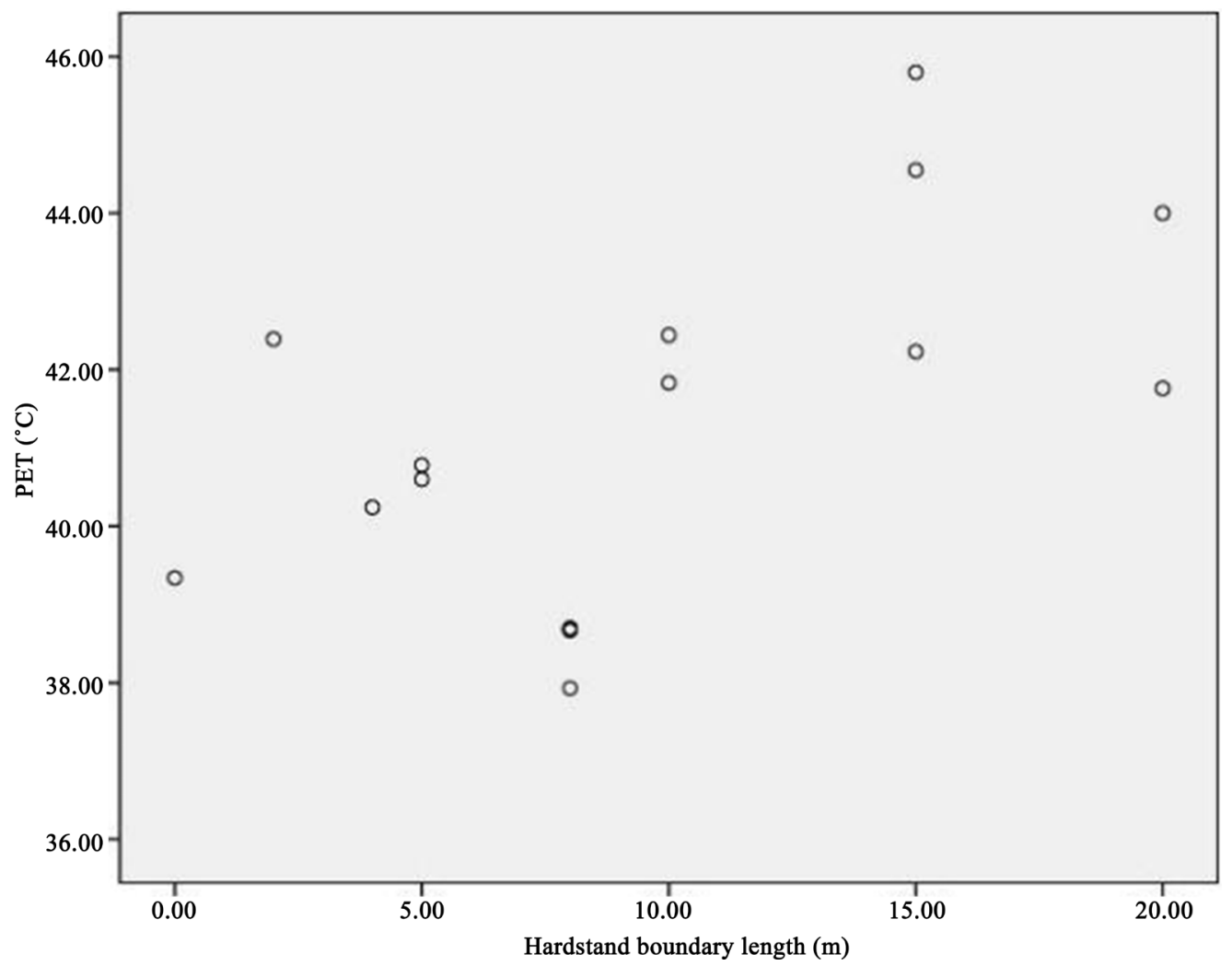

Figure 8. Correlation between pavement boundary length and PET. 


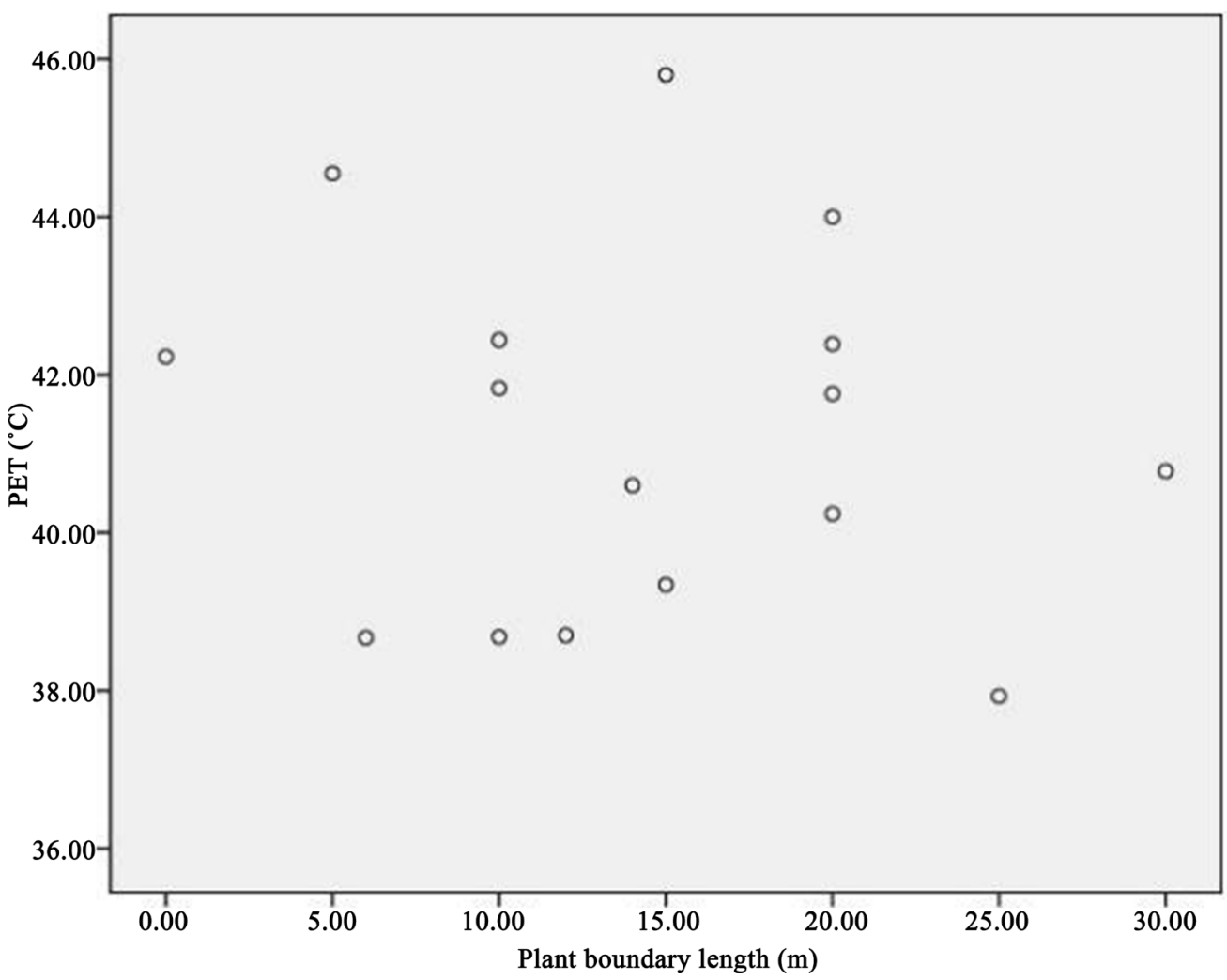

Figure 9. Correlation between the length of the structure boundary and PET.

equivalent temperature of the current space human body; and the correlation coefficient of the degree of shielding above the space is $-0.934<0$, which also shows negative correlation; in the underlying surface elements, there is a significant positive correlation between the hard stone brick paving area and the environmentally neutral PET value, and the correlation between the lawn area is weaker; while the environmental boundary and spatial microclimate do not exist. There is a significant correlation, and the bounding degree of the boundary is not easy to calculate, and the range of the selected spatial unit and the boundary are measured that will not be considered.

\subsection{Descriptive Statistics of Variables Related to Influencing Factors}

According to the results of the correlation analysis, shown in Table 6, it can be seen from Table 6 that there are significant correlations between the four variables and the PET value of the activity space. But making relevant analysis can only show that there is a relationship between the two. As for whether these variables can cause significant changes in the spatial microclimate, multiple linear regression analysis is needed on this basis.

\subsection{Regression Analysis of Related Variables}

The regression model can be expressed as: $Y_{i}=C+\alpha W_{i}+\beta C_{i}+\gamma G_{i}+\delta P_{i}+\varepsilon$. It is variable factors include water area, shade range, lawn area and stone brick area. 
Among them, the dependent variable $Y$ represents the number of people counted at each measuring point, and $i$ represents the number of the measuring point in the observation space. In order to ensure the integrity of the regression equation model, Set constant " $C$ " and random error value " $\mathcal{E}$ ". " $W$ " represents the variable water body area within the experimental range; " $C$ " represents the current spatial occlusion degree; “ $G$ " represents the size of the lawn area at different measuring points; " $P$ " represents the variable area of hard paving. " $\alpha, \beta, \gamma$ ", and " $\delta$ " respectively represent the regression coefficients of different variables. First, the variable groups that characterize the four types of elements are fitted separately, and then all the factors are fitted. The regression model analysis results that affect the elements are shown in Table 7.

From the analysis of the single variable factors in the data, this article selects that the respective variable models are basically consistent with the comprehensive model, indicating that the multivariate comprehensive model we established is generally stable. Among the three types of environmental landscape elements such as water body, underlying surface, and shading, the degree of shading of the place has the greatest impact on the thermal sensation value of tourists, and its fitting degree reaches 0.863 , it indicates that the change of the space-average PET

Table 6. Descriptive statistics.

\begin{tabular}{ccccc}
\hline & Min & Max & Value & Standard deviation \\
\hline PET $\left({ }^{\circ} \mathrm{C}\right)$ & 37.93 & 45.80 & 41.2462 & 2.30254 \\
Water area $\left(\mathrm{m}^{2}\right)$ & 0.00 & 30.00 & 10.4375 & 9.68827 \\
Shadowing area & 0.00 & 20.00 & 9.8750 & 6.21691 \\
Lawn area $\left(\mathrm{m}^{2}\right)$ & 5.00 & 76.00 & 45.8750 & 24.25387 \\
\hline
\end{tabular}

Table 7. Multiple regression model.

\begin{tabular}{|c|c|c|c|c|c|}
\hline \multirow{2}{*}{$\begin{array}{l}\text { Tepes of } \\
\text { landscape }\end{array}$} & \multicolumn{4}{|c|}{ Single independent variable model } & \multirow{2}{*}{$\begin{array}{c}\text { Comprehensive } \\
\text { model }\end{array}$} \\
\hline & Water area & $\begin{array}{c}\text { Shadowing } \\
\text { area }\end{array}$ & Lawn area & $\begin{array}{c}\text { Stone brick } \\
\text { area }\end{array}$ & \\
\hline wave & $\begin{array}{l}-0.210 \\
(0.000)\end{array}$ & & & & $\begin{array}{l}-0.113 \\
(0.043)\end{array}$ \\
\hline sunshade & & $\begin{array}{l}-0.346 \\
(0.000)\end{array}$ & & & $\begin{array}{l}-0.188 \\
(0.000)\end{array}$ \\
\hline $\begin{array}{l}\text { underlying } \\
\text { surface }\end{array}$ & & & $\begin{array}{l}-0.067 \\
(0.002)\end{array}$ & $\begin{array}{c}0.064 \\
(0.000)\end{array}$ & $\begin{array}{c}-0.045 \\
(0.398) \\
0.022 \\
(0.664)\end{array}$ \\
\hline $\mathrm{R}^{2}$ & 0.782 & 0.872 & 0.499 & 0.732 & 0.971 \\
\hline adjust $\mathrm{R}^{2}$ & 0.766 & 0.863 & 0.464 & 0.713 & 0.961 \\
\hline $\mathrm{N}$-value & 16 & 16 & 16 & 16 & 16 \\
\hline constant & 43.440 & 44.661 & 44.324 & 38.428 & 47.347 \\
\hline
\end{tabular}

Sig. Extremely significant level $\leq 0.01 * \star$. Sig. $<0.05$ significant level. 
mean $80 \%$ may be affected by the variable of the degree of space shielding, and the size of the water body in the space also has a strong effect of changing the environmental comfort; Compared with the underlying surface factor, the impact of the area of stone bricks on environmental comfort is significantly greater than the area of the lawn under the surface, but the area of stone bricks is positively related to the average value of space PET. When the installation area get larger, the PET value will also increase. The fitting degree of the comprehensive model reaches 0.961 , which is better than the fitting degree of each single factor model in the data listing, this number indicates that the combined influence of the comprehensive factors is more in line with the actual situation.

\subsection{Analysis of Research Results}

\subsubsection{Water Analysis}

Combining the correlation and regression analysis data of the water body area and the summer neutral PET range in Mianyang City, among the elements of the water body, the water body area in the space environment is an important reason to attract people to carry out activities. The number is -0.21 , indicating that the water area per unit area increases, and the physiologically equivalent temperature in the space is more suitable for the comfort threshold of Mianyang City. Combined with the survey situation, most active people prefer to take a rest on the hydrophilic platform or corridor at the edge of the water body. The actual feeling of the current environment from the actual distribution of the questionnaire also verified the authenticity of the model construction. We can analyze the reason from humidity adjustment. Water molecules flow with the flow of air. The flowing air plays the role of dispersing water molecules. As the water evaporates, it reduces the concentration of water molecules in the surface air and plays a role in regional humidity. Secondly, the temperature difference between the water body and the surrounding environment forms a land and water breeze. The wind will make people feel cool, and the body and mind are pleasant.

\subsubsection{Shade}

Combining correlation and regression analysis results, the factor of shading is 0.863 , indicating that it has the most important impact on recreational activities. The reason for the analysis is that the large trees in the upper layer of the space can block the sunlight, avoiding direct sunlight in the hot summer, and provide a large space for activities under the canopy. The surrounding of the site is equipped with lawns or small shrubs to enclose the space. This kind of collocation has a sense of security and does not block the line of sight, giving people a comfortable feeling; while using the building as a shaded space, on the one hand, the building can block most direct sunlight, under the shadow of the building, the temperature of solar radiation. It is obviously lower than the uncovered place. At the same time, in the enclosed area of the building, courtyard wind will also be formed due to the temperature difference. In the park, seats for people to relax are usually set in a cool place. When people are hot or tired, they will choose 
such a place to stay and play, so the number of people gathered here will be more.

\subsubsection{Underlay}

Combining the calculation results of correlation and regression analysis, we found that the correlation coefficient is 0.464 when the underlying surface is lawn and 0.713 when it is stone brick. There is a certain influence. When the hard slate pavement is used as the underlay, when its pavement area exceeds $20 \%$, the larger the area, the greater its negative significance coefficient, indicating that it is negatively related to space comfort related. This is because the reflected heat of the slate raises the temperature of the already hot air. We know that temperature is a key factor that affects people's thermal sensation in the environment. At the same time, because of the poor water retention of the slate, the dryness of the venue makes the hotness. People are more uncomfortable, so we found that the number of people gathering and staying in hard-paved venues will be less in hot summer weather. Compared with all the lawn areas in the park, there are relatively many people who are recreational. The results of regression calculation show that when the lawn pavement area of the site exceeds $20 \%$, the calculated PET average value is significantly closer to the summer PET neutral value in Mianyang. There will also be more people moving in the current place. The lawn has a cool climate due to its own characteristics. At the same time, it will also form a flowing wind due to the temperature difference, making people feel comfortable. It can also be explained from psychological activities. People who live in the city for a long time prefer outdoor activities close to nature.

\section{Discussion}

This study is an objective and scientific study. It attempts to quantify and quantify the environmental factors of parks that affect human behavior surely. This study also has deficiencies:

1) At present, we only study some of the spatial environment elements in the actual spatial environment, do not take people's psychological activities, thermal preferences and other reasons for activities into account [17]. Due to the influence of the reasons, I hope that the next research survey can conduct a more comprehensive correlation study, which can lead to a more complete thermal environment impact mechanism for tourists and provide a theoretical basis for the planning and optimization of urban parks.

2) For the survey and research based on the 2019 summer data of urban parks in Mianyang City only, the time for field measurement of climate data is relatively short, and the study area has certain limitations, so the results can be applied to certain extent limitations [18]. We hope to collect more urban park space samples in the next step, and we can get a more general conclusion. Some new technologies are gradually applied to the research of outdoor thermal comfort [19]. 


\section{Conclusions}

Through field measurements, data analysis, and result research on the four parks in Mianyang City, we carried out meteorological data measurements on the field and quantified statistics on the number of people in various venues and the elements of the recreational space environment, and we use computer software to explore the thermal sensation in the current space by analyzing the influence of spatial environment on different elements. We found that the way to set water bodies is the most important factor that affects people's behaviors. So, we can emphasize the design of the park, and the use of the shading effect of plants and buildings to improve the current microclimate is also effective, but it will be restricted to a certain extent due to the terrain and the overall planning of the park. The setting of the underlying surface of the event venue will also affect people's thermal feelings in different levels.

In China, they usually take the number of tourists and the space capacity into consideration in urban parks design. The general minimum requirement is 500 square meters per 10,000 people in general. We found that there is a lack of facilities and other requirements in the specification. At the same time, there is no support for standards and theoretical data in this regard. From the design uncomfortable environment of the park in Mianyang, may waste space for lacking the rest space and needs to tourists, and even cause a waste of resources. From the results of the analysis, we consider the influence of different spatial elements on the comfort of space, optimize the current location to configuration design of space environment elements, and reduce the unreasonable design, low utilization rate or uncomfortable space in urban parks. Besides, from the point of view of microclimate to improve the using rates and comfort of the venue to attract tourists meet the needs and experiences of tourists leisure and play.

In order to provide users with a comfortable playing environment and improve the utilization rate of urban parks, we propose some strategies for optimizing the space design of parks according to the different elements of the park space environment:

1) The flat terrain of the park can be set up for visitors to gather and disperse, and the underlying surface can be set up as a large-scale lawn to meet the needs of urban residents to be close to nature, and provide a place for parents and children to interact and play.

2) Secondly, when a large area of hard pavement is needed in the park, some accessible lawns, soft plastics, etc. can be added in appropriate amounts. At the same time, permeable bricks can also be considered, and part of the rain water flow can be directly used for greening. For irrigation with plants, the other part is stored in the soil below, and the microclimate of the space is adjusted by transpiration. This arrangement is beneficial to meet the space usage requirements of the users of the active space formed by aggregation.

3) It is recommended that urban parks in the Mianyang area use water bodies to create landscapes, use rivers in the city to connect with low-lying areas in the 
park to form living water spaces, build hydrophilic platforms, and create rich water features, thus avoiding the occurrence of eutrophication of water bodies, to improve water quality, but also improve the environmental quality of urban parks.

4) In the planning of the park, it is not possible to blindly pursue high green space rates and large areas of shrubs and shrubs to enrich vegetation. It is recommended to use large trees + lawns for the construction of open spaces. This will not only provide people with visual permeability, but also allow more shade for the recreational space, avoiding direct sunlight in the hot summer. It is recommended to use the tree + ecological tree pond design under the large tree with the branches and leaves extended to create a comfortable and relaxing environment for those who want to take a short break.

5) It is recommended that the buildings in the park provide users with space to shelter from the wind and rain while increasing permeability and forming a ventilated corridor. At the same time, it is recommended to arrange some garden sketches in such a space to form a harmonious environment in which people and nature form an interesting shape.

\section{Acknowledgements}

This paper was funded by the key R\&D project in the field of social development in Sichuan Province in 2020. The project name: "Research on the Green Livable Performance Improvement Technology of the Northwest Sichuan Plateau Villages and Towns", No. 2020YFS0308. Thanks to the citizens of Mianyang who participated in the survey and the researchers who participated in the survey, including Yao Wei, Huang Zefeng, Feng Qiushuang, etc.

\section{Conflicts of Interest}

The authors declare no conflicts of interest regarding the publication of this paper.

\section{References}

[1] He, B.-J., Ding, L. and Prasad, D. (2020) Outdoor Thermal Environment of an Open Space under Sea Breeze: A Mobile Experience in a Coastal City of Sydney, Australia. Urban Climate, 31, Article ID: 100567. https://doi.org/10.1016/j.uclim.2019.100567

[2] Yang, S. and Lin, T. (2016) An Integrated Outdoor Spaces Design Procedure to Relieve Heat Stress in Hot and Humid Regions. Building and Environment, 99, 149-160. https://doi.org/10.1016/j.buildenv.2016.01.001

[3] Nouri, A.S. and Costa, J.P. (2017) Addressing Thermophysiological Thresholds and Psychological Aspects during Hot and Dry Mediterranean Summers through Public Space Design: The Case of Rossio. Building and Environment, 118, 67-90. https://doi.org/10.1016/j.buildenv.2017.03.027

[4] Hirashima, S.Q.D.S., Assis, E.S.D. and Nikolopoulou, M. (2016) Daytime Thermal Comfort in Urban Spaces: A Field Study in Brazil. Building and Environment, 107, 245-253. https://doi.org/10.1016/j.buildenv.2016.08.006

[5] Chen, L., Wen, Y., Zhang, L., et al. (2015) Studies of Thermal Comfort and Space Use in an Urban Park Square in Cool and Cold Seasons in Shanghai. Building and 
Environment, 94, 644-653. https://doi.org/10.1016/j.buildenv.2015.10.020

[6] Martinelli, L., Lin, T. and Matzarakis, A. (2015) Assessment of the Influence of Daily Shadings Pattern on Human Thermal Comfort and Attendance in Rome during Summer Period. Building and Environment, 92, 30-38. https://doi.org/10.1016/j.buildenv.2015.04.013

[7] Mahmoud, A.H.A. (2011) Analysis of the Microclimatic and Human Comfort Conditions in an Urban Park in Hot and Arid Regions. Building and Environment, 46, 2641-2656. https://doi.org/10.1016/j.buildenv.2011.06.025

[8] Rodríguez Algeciras, J.A., Gómez Consuegra, L. and Matzarakis, A. (2016) Spatial-Temporal Study on the Effects of Urban Street Configurations on Human Thermal Comfort in the World Heritage City of Camagüey-Cuba. Building and Environment, 101, 85-101. https://doi.org/10.1016/j.buildenv.2016.02.026

[9] Xu, M., Hong, B., Mi, J., et al. (2018) Outdoor Thermal Comfort in an Urban Park during Winter in Cold Regions of China. Sustainable Cities and Society, 43, 208-220. https://doi.org/10.1016/j.scs.2018.08.034

[10] Nam, I., Yang, J., Lee, D., et al. (2015) A Study on the Thermal Comfort and Clothing Insulation Characteristics of Preschool Children in Korea. Building and Environment, 92, 724-733. https://doi.org/10.1016/j.buildenv.2015.05.041

[11] Lin, T. (2009) Thermal Perception, Adaptation and Attendance in a Public Square in Hot and Humid Regions. Building and Environment, 44, 2017-2026.

https://doi.org/10.1016/j.buildenv.2009.02.004

[12] Chan, S.Y., Chau, C.K. and Leung, T.M. (2017) On the Study of Thermal Comfort and Perceptions of Environmental Features in Urban Parks: A Structural Equation Modeling Approach. Building and Environment, 122, 171-183. https://doi.org/10.1016/j.buildenv.2017.06.014

[13] Xu, X., Sun, S., Liu, W., et al. (2017) The Cooling and Energy Saving Effect of Landscape Design Parameters of Urban Park in Summer: A Case of Beijing, China. Energy and Buildings, 149, 91-100. https://doi.org/10.1016/j.enbuild.2017.05.052

[14] Hwang, Y.H., Lum, Q.J.G. and Chan, Y.K.D. (2015) Micro-Scale Thermal Performance of Tropical Urban Parks in Singapore. Building and Environment, 94, 467-476. https://doi.org/10.1016/j.buildenv.2015.10.003

[15] Klemm, W., Heusinkveld, B.G., Lenzholzer, S., et al. (2015) Psychological and Physical Impact of Urban Green Spaces on Outdoor Thermal Comfort during Summertime in the Netherlands. Building and Environment, 83, 120-128. https://doi.org/10.1016/j.buildenv.2014.05.013

[16] Cheng, B., et al. (2019) Thermal Comfort in Urban Mountain Parks in the Hot Summer and Cold Winter Climate. Sustainable Cities and Society, 51, 1-17. https://doi.org/10.1016/j.scs.2019.101756

[17] Lin, T., Tsai, K., Liao, C., et al. (2013) Effects of Thermal Comfort and Adaptation on Park Attendance Regarding Different Shading Levels and Activity Types. Building and Environment, 59, 599-611. https://doi.org/10.1016/j.buildenv.2012.10.005

[18] Zhang, A., Bokel, R., van den Dobbelsteen, A., et al. (2017) An Integrated School and Schoolyard Design Method for Summer Thermal Comfort and Energy Efficiency in Northern China. Building and Environment, 124, 369-387. https://doi.org/10.1016/j.buildenv.2017.08.024

[19] Niu, J., Liu, J., Lee, T., et al. (2015) A New Method to Assess Spatial Variations of Outdoor Thermal Comfort: Onsite Monitoring Results and Implications for Precinct Planning. Building and Environment, 91, 263-270.

https://doi.org/10.1016/j.buildenv.2015.02.017 